\title{
Flight to Canada: Young Survivors of War and Violent Oppression
}

\author{
Susan Beattie
}

Immigrants who have lived through war, violent oppression or flight because of fear of persecution before coming to Canada, have had experiences in common that cut across the lines of nationality, culture, ethnicity or gender. Within this group, adolescents are at a unique vantage point from which to review their experiences. They are close enough to childhood to see recent traumatic events in sharp contrast to an earlier and probably more settled past, and old enough to have an understanding of the very real peril that they have lived through. For many the journey or escape from danger or persecution becomes the focal point and central event of their lives. Their stories add detail and a perspective not frequently encountered to the history of immigration to Canada.

This paper is based on oral interviews conducted with about twenty-five young men and women, aged fourteen to nineteen, from twelve countries in East and South Asia, Africa, the Middle East, Central Europe and Latin America. The experiences and cultures of these young people are diverse, but they have all had to leave or escape from potentially life-threatening situations, and they all now live in Ontario. The names of the individuals have been changed, and usually their region of origin rather than their country is given. Stories have not been combined and no details have been added.

Teenagers who travelled with others, whether parents, surrogate parents, casual companions or hired travel agents, did not necessarily have an easier time before or during their journey than those who travelled alone, but the

Susan Beattie is a teacher with the Peel Board of Education and is doing graduate work at the Ontario Institute for Studies in Education. She is also Secretary of the Canadian Centre for Victims of Torture. presence of family members or others gave support and strategies that helped them survive during their ordeal. Mari, a young teenager, and her family had a precipitous departure from Kuwait at the end of 1990, just prior to the onset of the Gulf War. When Iraqi army trucks pulled up outside her house, her father simply gave over the house and car keys to the commanding officer who was "very polite." Her father asked for and was allowed to keep enough money to travel to the end of the bus line, and from there the family - parents, Mari, and her brother and sister - walked across the desert to Jordan. The journey took them three days. Eventually their water ran many weeks because of the severity of his injuries, and Ramon and his mother, believing the assailants to be off-duty police, were afraid to report the incident. They brought a doctor to the house to stitch the father's wounds and then concealed and tended him until he could travel. They left their home in the night and made their way to a safe country. There Ramon supported the family for three years by working as a short-order cook. His mother and father were unable to work steadily during this period, and his sister was too young.

Some families made the decision to leave or send away one of their children only after several months or years of

\section{A number of young teenagers travelled to Canada in the care of surrogate parents or hired companions. They had been sent away to escape civil war or the brutality of insurgent armies, often after others in their families had been killed or coerced into service.}

out, but they were able to reach a refugee camp before they became dangerously dehydrated. Although they were threatened, they were physically unharmed, but they lost their possessions accumulated over thirty years. They arrived in Jordan with only the clothes they wore. They considered themselves lucky not to have suffered physical assault or worse. They reached Canada within three weeks of leaving their home.

Other families were relatively less fortunate. For some, harassment turned into violent assault when the policecould or would no longer provide protection. When Ramon, a fifteen-year-old Latin American, and his family were threatened and harassed, they began to fear for their safety. One night their house was broken into and Ramon's father was beaten severely and left for dead. The rest of the family was unharmed but terrified. Ramon's father was unable to travel for trouble rather than as the result of one terrifying or brutal incident. Alicia and her family left their home and grocery store in a Caribbean country after a prolonged period of harassment. She was eleven when harassment escalated into a series of violent incidents that led to her family's eventual decision to leave. "It was September, I think it was a holiday. We made good money that day. There were three men that came in the store, and my dad tried to defend himself. He was cut on his cheek; he got twenty-fourstitches for it; he got his head split open." Alicia ran to a neighbour's house for help, but when two men started running after her, she hid behind the house until they left. A few months later "Christmas day or the eve before Christmas, we were sleeping, and around two in the morning we heard a bang. We thought it sounded like a gunshot. Then when I jumped out of my bed somebody banged my door and it

Refuge, Vol. 12, No. 3 (September 1992) 
opened, and there was a man with a gun by my throat." Alicia's parents were violently assaulted and robbed. Alicia hid under herbrother's bed. The children could do nothing to defend their parents, and the police could notbecalled because her parents feared they "had a hand in it." Alicia, her parents and younger brothers were able to get travel documents, including passports, and they sold their business and possessions to buy round-trip tickets to Toronto. Three years after their trouble began, they left their home with two suitcases and the clothes they were wearing.

These young people and their families benefitted from the considerable social and often material support they and-rug dealer with whom he stayed for over a year, earning his keep by running errands and sweeping up. He slept in a corner of the store. From there he was eventually collected by a "family friend" and taken to Toronto. When they arrived at the airport, the friend and Hassan's documents vanished. Hassan, by then fourteen years old, spent a month in detention and was then taken into care by the Children's Aid Society and placed in a foster home. Though separated from his family and in danger during his journey over the mountains, Hassan was never directly threatened, nor did he have to make travel arrangements or crucial decisions on his own or find food and shelter. Perhaps these reasons

\section{For many the journey or escape from danger or persecution becomes the focal point and central event of their lives. Their stories add detail and a perspective not frequently encountered to the history of immigration to Canada.}

gave one another. A number of young teenagers travelled to Canada in the care of surrogate parents or hired companions. They had been sent away to escape civil war or the brutality of insurgent armies, often after others in their families had been killed or coerced into service. For some of them the journey turned into a kind of adventure, perhaps because they had not suffered directly, were still very young, or bore no responsibility for making decisions. Their adult companions carried their documents and talked to immigration officials.

Hassan's family sent him away from his Middle-Eastern home in 1988 when he was twelve years old. His country was involved in a seemingly unending war, and his parents feared he was in danger of being forced to join the army or of being removed from home to live in a training camp, as had happened to other boys in his village. He travelled with a guide over mountains by night, hiding in the day. Silence was necessary at all times because the terrain was patrolled by soldiers. Upon arrival in a safe country, Hassan's guide left him with a furniture- explain in part why he looks back on his experience of flight and travel with what might almost be described as a sense of adventure.

Rajuh's experience was similar but briefer. Rajuh was fifteen at the time of his departure from South Asia. He travelled to Canada on a round-theworld ticket with an "aunt" who had been hired by the travel agent who arranged his trip. Rajuh's parents sent him away because renegade soldiers were making door-to-door searches of all the houses in his village and forcing boys to join their army. The hired aunt kept his travel documents and did all the talking to officials at stopovers along the way. When Rajuh arrived in Toronto, his aunt and his travel documents disappeared. He did not spend time in detention, however, because he was met at the airport by a relative who had lived in Canada for three years and who immediately claimed refugee status for him.

The majority of adolescents described in this paper made their way to Canada alone. For them the journey was sometimes almost as harrowing as the events leading up to it. It often followed a period of acute suffering resulting from an injury or family loss. Some young travellers were still in poor health at the time of their departure or were afraid to admit any knowledge of English after their arrival. They feared immediate deportation, particularly if they carried false documents or had destroyed them during the flight. Others were able to find companions along the way, people from whom they gained information and confidence. For most, fear was a constant companion.

A few of the survivors of war or violence who arrived alone were young women who were on their way to join a relative or who were sent away by their families for their own safety. Muna fled to Canada from Somalia when she was eighteen. Her large family was being broken up by the continuous fighting, and her parents reasoned that it would be better to send one of their children to safety than none. They were able to put together enough money to buy the necessary travel documents, and they chose to send Muna because she was the oldest and the healthiest of the children. She was never in danger of deportation, but she destroyed her documents before landing as a precaution.

Whether male or female, all these youths' lives were touched by luck and danger. For Zhang, the route through which he escaped from China resulted in a journey that was complicated and dangerous. Zhangwas sixteen at the time of the Tiananmen Square massacre in 1989. He participated in activities in the square and took pictures of some of the events and people. His mother, a doctor, was in Canada on a fellowship, and his father was in the United States. Zhang decided he had to leave Chinabecause he believed he was being watched and was in danger of being arrested or worse. He left Beijing and travelled south toward Hong Kong, carrying the undeveloped film. When he reached Taishan, where he spoke the local dialect, he managed to give the film to a pilot who was leaving the country. Then he hid in the bottom of a boat going to Macao, and from there he was able to contact his mother and fly to Canada. 
Some of the youths were in poor health at the time of their departure and the pressures of the journey were often too much for them. Sometimes, though, luck turned in their favour. Param was sixteen when he left his home in South Asia. He had not fully recovered from serious wounds inflicted by assassins who killed his father and brother. Not only was he mourning their loss, but he knew that next time the bullets would not miss him. He obtained a false passport and a round-the-world ticket with a stop in Toronto. Param got only as far as the first stop on his journey, a city in Malaysia. Frightened and alone, and with documents that were obviously phoney, he broke down and confessed this to the airport immigration officer who questioned him. "He knew right away my papers were false. I couldn'tlie. I told him what had happened everything." The officer stamped his passport and allowed him to continue his journey.

Hari, also from South Asia, was seventeen when he fled from his home, having miraculously and unexpectedly survived brutal treatment by a terrorist group. His extended trip, arranged by "a clever travel agent," took him to the United States by way of Japan. Once airborne after leaving Tokyo he flushed his passport. When he arrived in Los Angeles without documents and afraid to reveal his knowledge of English, he was taken in handcuffs and leg-irons to detention. By then bewildered, afraid of being deported, and thinking he was going to prison, he broke down. "I was bawling," he said. Eventually a relative in Canada secured his release and he was allowed to travel to Ontario where he claimed refugee status.

Some youths managed to join other travellers for temporary companionship or mutual support at different times during their travels. As a result they reached Canada safely when they otherwise might not have, and they probably suffered less emotional trauma during the journey than those who were alone. Ahmal was one such youth. $\mathrm{He}$ left his town in a central African country in 1988 when he was fourteen, following the death of his mother and grandmother: "There was no one looking around after me because after my mom died, I was living with my grandma. She died in July and I had a problem there in the town, eating and all that." Sometimes neighbours gave him food, or he helped a local mechanic, "like if hewants a spanner or something," who gave him a little money to buy bread and milk, but when rebel troops came out of the forest, he decided to leave. "It happened that they wanted to capture me, but luckily I got a chance to get out from that place and I went to another house. I didn't even know whose house it was, but I climbed up on the roof and I hid myself about eight hours until they go out of Africa, like going somewhere far away from Africa where there is peace. Now I started thinking, where could it be? And I thought of Canada. I think it'll be the best place for me because I have never heard of anything about Canada like bombing and all this stuff. In the U.S. I know we used to see cinemas and fighting and things on the streets." By now it was late August 1988. Ahmal had been sleeping outdoors at night and was wholly dependent on others for food. He had no money of his own. "Money was the problem, and I had no document to travel with. So I decided to raise some money for myself. Every day after every prayer - because we pray

\section{Param was sixteen when he left his home in South Asia. He had not fully recovered from serious wounds inflicted by assassins who killed his father and brother. Not only was he mourning their loss, but he knew that next time the bullets would not miss him.}

were gone from the place.... I saw them coming. I saw them catching some other people."

Ahmal then left his town and made his way to the main road, where he helped two truck drivers fix a flat tire, and in turn got a lift to within a few kilometres of the border. There the truckers stopped for food, "and the drivers told me, 'Now what are you going to do? You can't cross without any documents?' I told them, 'No problem. I'll just stay here for a couple of hours and then I'll cross through the bush, through the forest.' That's what I did." For Ahmal, walking through the forest was as frightening as other parts of his journey. "It was dangerous because of the wild animals. I was afraid to cross by myself till I saw some other people crossing too. And right there at the border there was a fight. People have been slaughtered by the rebels; people were running across the border." He and his small group crossed at a different place.

Once in a safe country, Ahmal made his way to the capital city, asking for food and shelter in mosques along the way. It was then that he had the idea of leaving Africa. "Then it came to me that I want to five times - I used to have my small carpet for praying and they throw money on that after every prayer.... Some help and some don't. So that is the wayl raised my money."

By November Ahmal had enough money and street information to buy a passport and an airplane ticket to Toronto. He found a travelling companion, an eighteen-year-old who "also did the same thing as what I did. He was on the same flight I was on. I collected his passport and I sat with him. It was a seventeen-hour flight. I needed someone to talk to." Upon his arrival in Toronto, Ahmal was held overnight in detention and released the next morning as a ward of the Children's Aid Society. Because he was under sixteen he was placed in a foster home. Ahmal's ability to make contact with groups and individuals throughout his journey partially explains its successful outcome, but luck also played a significant part throughout his complex and remarkable odyssey.

The young people whose stories are told in this paper have been in Canada for fewer than four years and, in some cases, only for a month or two. While it is

Refuge, Vol. 12, No. 3 (September 1992) 
too early to comment on how their past experiences have affected their present lives, it is nevertheless interesting to note what has become of them, particularly in relation to school attendance, something each of them considered important.

Mari is still in high school. Her parents have no plans to return to Kuwait; but whether or not they will receive compensation for their losses is not known. Ramon was granted several high school credits for his years of work, reducing the time he needed to earn a diploma. As a result he was able to graduate from high school recently. $\mathrm{He}$ didnot continuehis education, buthopes to do so one day. For now he wants to work to help support his family. His mother is also working. Hassan and Rajuh are learning English and progressing through high school. Hassan has been granted landedimmigrant status. Rajuh's case is still pending, but it seems unlikely that he will be deported. Alicia and Zhang will both graduate in June. Alicia's parents have found steady work, making it possible for Alicia to devote herself full time to her studies. Earlier in the year she tried to work the night shift at a factory to help out, but quit when her marks began to suffer. She hopes to go to college. Zhang and his mother applied for landed-immigrant status after his safe arrival in Canada, something his mother had been afraid to do while he was still in China. Zhang plans to attend university next year.

Muna, Param, Hari and A hmal were unable to continue their studies. Muna could not afford to leave herjob as a night cook or risk losing it by shortening her hours. Having made contact with one of her brothers and learned that several others in the family were safe, she considered her first obligation to help them by sending money when she could. Param's health remained fragile. After three operations and an attack of malaria, which required several weeks of hospitalization, he decided he could not continue in school. He lives with a group of young men from his home country, all of whom are working, and he is largely responsible for his own care. Hari, now eighteen, has not yet received permission from immigration to attend school. Because of his intense desire to study, it is likely that he will do so once his claim is resolved. Ahmal left school when he turned sixteen. While in foster homes, he so missed the companionship and culture of others who speak his own language that he moved in with a group of older refugee claimants from his country of origin who were living together in Toronto. In doing so he lost his benefits and was obliged to go to work.

These young men and women, at the threshold of their adult lives, have endured situations that most adults in Canada will never encounter. As varied as their experiences were, they had in common persecution or assault of such severity that they fled from their home countries to save their lives. Their journeys varied in duration and intensity, but they shared and eventually achieved one common goal: to reach Canada. The evidence from their stories suggests that those who travelled with others - whether family, surrogate parents, a hired travel agent or a chance companion - fared better during their journey than those who were alone. It also suggests that those who had an adult or family to live with after they arrived were more likely to stay in school and to graduate. A partial explanation might be found in the simple support and encouragement a family-like relationship can provide, and in the attention it can give to the needs and routines of daily life: enough to eat, regular meals, help with getting up and out in the morning, the expectation of homework, a place to study and the conviction that doing so has value and, last but not least, sociability.

In many ways the experiences of these young men and women reflect the struggle and uncertainty of other young immigrants who have for generations journeyed to Canada, but in addition they have had to live with the unceasing presence of the violent oppression that drove them from their homeland. Alicia, for whom night is often still frightening, spoke for all of them without intentional irony when she said, "You do have your memories."

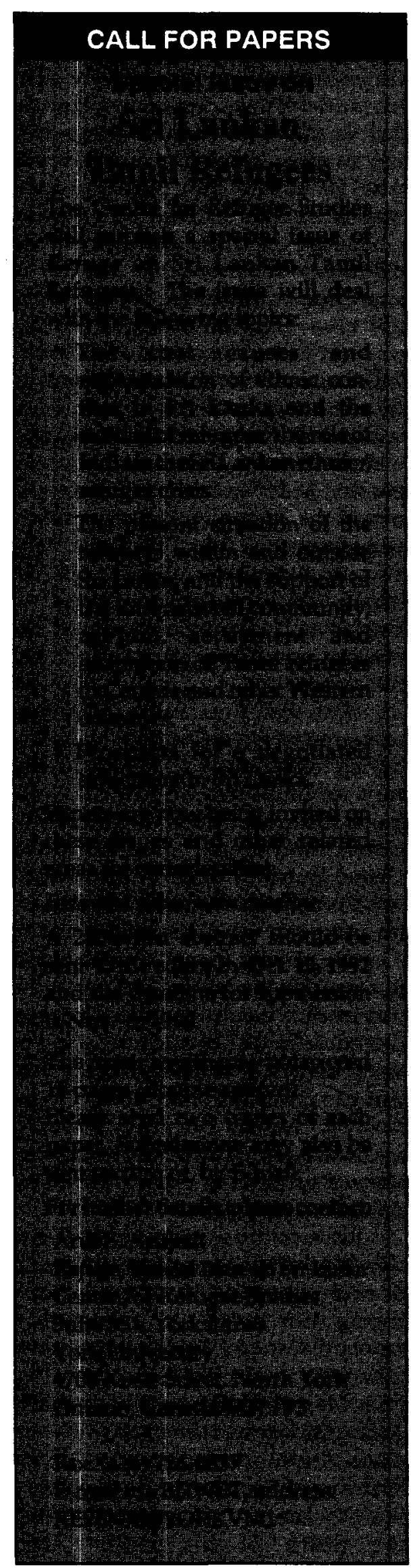

